Vol. 1, No. 1, March 2019 e-ISSN: 2656-4882 p-ISSN: 2656-5935

\title{
BITCOIN-USD Trading Using SVM to Detect The Current day's Trend in The Market
}

\author{
Ferdiansyah $^{1}$, Edi Surya Negara ${ }^{2}$, Yeni Widyanti ${ }^{3}$
}

\author{
${ }^{1}$ Informatics Department, Bina Darma University, Palembang, Indonesia \\ 2Information System Department, Bina Darma University, Palembang, Idnonesia \\ ${ }^{3}$ Acounting Department, Bina Darma University, Palembang, Idnonesia \\ Email:1 1ferdi@binadarma.ac.id, 2e.s.negara@binadarma.ac.id, ${ }^{3}$ yeni_widyanti@binadarma.ac.id
}

\begin{abstract}
Bitcoin is a kind of Cryptocurrency and now is one of type of investment in the stock market. Stock markets are influenced by many risks of factor. And bitcoin is one kind of cryptocurrency that keep rising in recent few years, and sometimes fall without knowing influence behind it, on stock market. Because it's fluctuations, there's a need Automated tool to prediction of bitcoin on stock market. However, because of its volatility, there's a need for a prediction tool for investors to help them consider investment decisions for bitcoin or another cryptocurrency trade. The predict methods will be used on this research is regime prediction to develop model to predict trend at the opening of market using SVM.
\end{abstract}

Keywords: Cryptocurrency, Prediction Bitcoin, SVM

\section{INTRODUCTION}

The one of unique characteristics of bitcoin is keep rising in the last few years. Bitcoin exchange rate (USD) is $\$ 3990$ USD on November 2018 and daily fluctuations could reach $4.55 \% 2$ [1]. It's interesting to predict value to determine profitable investment for investor. To solve the problem above, there's a need a tool for predictoon to help investors decide for bitcoin or other cryptocurrency market investment. Market technical analysis can determine the trend of the market in by using historical market price [2]. They give the candle graph and market indicator to help the analysis. Even market technical analysis is useful, Therefore, another automation method is needed[3], because There has been much research about SVM prediction, Machine learning provides capability produce results of predictions more accurately without expert. In this research we use machine learning and use data history from yahoo-finance, and train with Support Vector Machine, SVM is one of the popular machine learning to used predict future and current trends in stock market [4] [5] and we combine with regime algorithm [6] [7] to predict Bitcoin-USD current day's trend on yahoo-finance stock market. 


\section{METHODS}

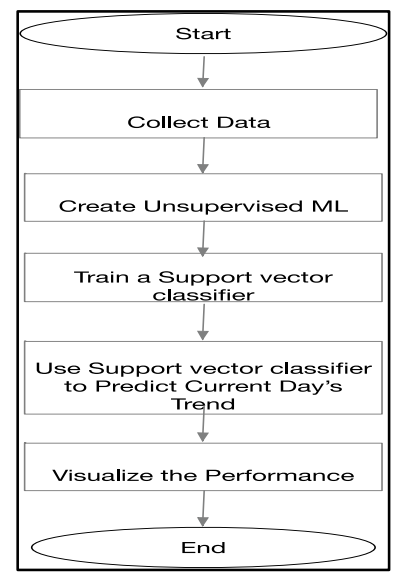

Figure 1. Methods

\subsection{Research Methods}

\subsubsection{Dataset}

Dataset is from yahoo finance, we take period 4 years, because at 2014 the data is having too many Nan values, so is not good to train the data with many missing values or called NAN, and will impact to the results. we take the data with symbol "BTC-USD" and saved it as df (dataframe), we choose duration from the year 2015 until 2019.

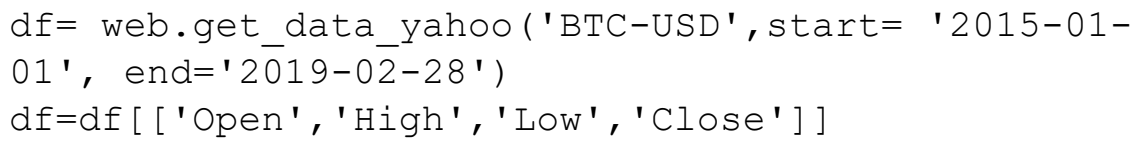

We created variable indicators to used as features for training the algorithm. Before that we decided to select look back period of 10 days, we select 10 to check for the past 2 weeks of trading data and to prevent the noise.

$$
\begin{aligned}
& n=10 \\
& t=0.8 \\
& \text { split }=\text { int }(t * l e n(d f))
\end{aligned}
$$

We move the High, Low and Columns by one, to access the past data, we created RSI, SMA, ADX, Correlation, SAR and back to the return the past one day. And this is the result: 
Vol. 1, No. 1, March 2019

p-ISSN: 2656-5935 http://journal-isi.org/index.php/isi e-ISSN: 2656-4882

Table 1. Sample Result from collect Data

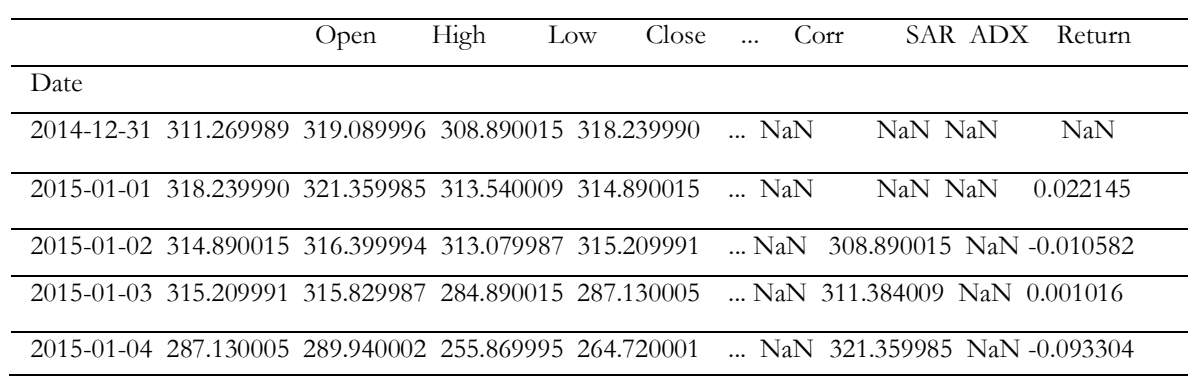

There are many Nan Values. We need to drop them. we droppend the $\mathrm{NaN}$ values with this command algorithm.

$$
d f=d f \cdot d r o p n a()
$$

\subsubsection{Create Unsupervised Machine Learning}

We continue on used a Standard Scaler and make an unsupervised learning to create trend prediction[8]. We printed the average and covariance value feature and this is the results:

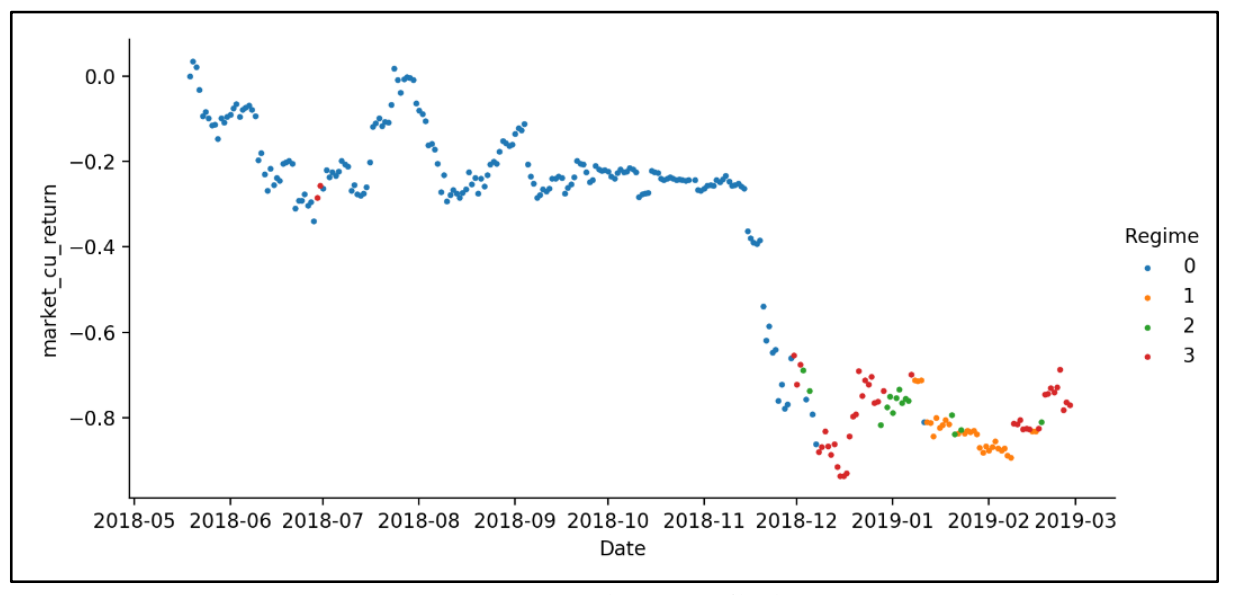

Based on fig.2

Figure 2. Regime prediction

1. The red color for low volatility.

2. The purple color for high volatility..

3. The green color for breakout.

('Mean for regime 0: ', 1.4263478931206095) 
('Co-Variance for regime 0: ', 1.2409273396350549$)$

('Mean for regime 1: ', -0.519033358676531)

('Co-Variance for regime 1: ', 0.15086596332070093$)$

('Mean for regime 2: ', -0.48168648538272163)

('Co-Variance for regime 2: ', 0.16917162258686008$)$

('Mean for regime 3: ', -0.4206341985600407 )

('Co-Variance for regime 3: ', 0.2583432643923261$)$

Table 2. Mean Regime results

\begin{tabular}{ccccc}
\hline Date Regime & & $\ldots$ & \multicolumn{2}{c}{ Return market_cu_return } \\
\hline $0.2018-05-19$ & 0 & $\ldots$ & 0.000161 & 0.000161 \\
\hline $12018-05-20$ & 0 & $\ldots$ & 0.033846 & 0.034007 \\
\hline $32018-05-21$ & 0 & $\ldots$ & -0.013396 & 0.020611 \\
\hline $32018-05-22$ & 0 & $\ldots$ & -0.052036 & -0.031425 \\
\hline $42018-05-23$ & 0 & $\ldots$ & -0.062863 & -0.094288 \\
\hline
\end{tabular}

\subsubsection{Train in Support Vector Classifier}

Next, we predict the rules of regimes data frame, excluding the Date and Regimes columns,

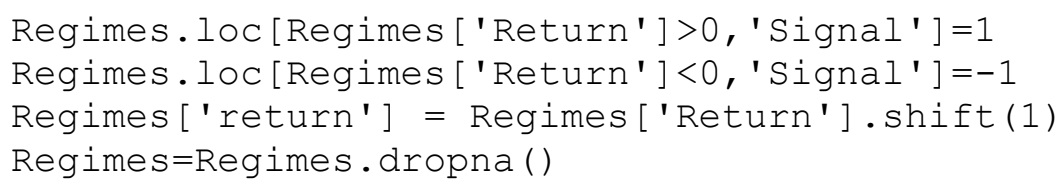

We continue with a SVC. That represented by sklearn.

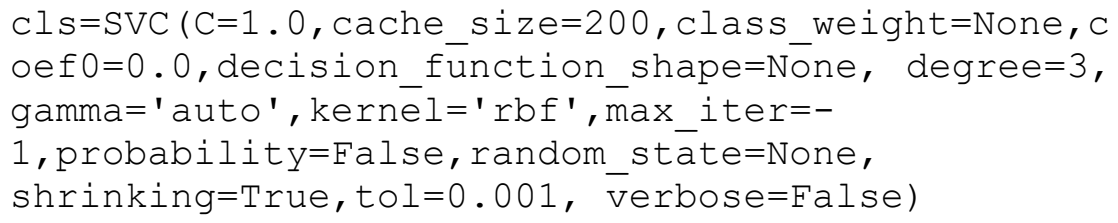

Support Vector Machine (SVM) is a discriminative classifier that generates a separating hyper-plane. Error tolerance budget is included to make separating hyperplane robust in case of inseparable class data. Linear decision boundaries are augmented to more complex boundary shape through kernel implementation (e.g. polynomial, Gaussian and radial kernel). SVMs have received attention for the impressive performance in classification. Below is formulation of the optimization and constraint model for SVM [9]. 


$$
\min _{y, w, b} \frac{1}{2}\|\omega\|^{2}+\mathbb{C} \sum_{\mathfrak{i}=1}^{\mathfrak{m}} \xi \mathfrak{i}
$$

s.t. $y^{\mathrm{i}}\left(\omega^{T} x^{\mathrm{i}}+b\right) \geq 1-\xi_{\mathrm{i}}, i=1, \ldots, m \xi_{i} \geq 0, i=1, \ldots, m$.

We divide the test data from the unsupervised trend algorithm into train data and tests.

\section{'Signal' 'Return' 'market cu return' ' Date'}

Then we fit the $\mathrm{X}$ and $\mathrm{y}$ data sets to the algorithm to train it on

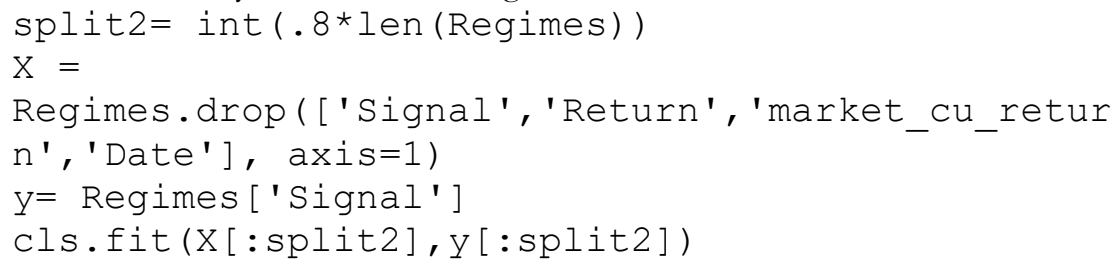

We calculated the size of test sets and predictions indexed accordingly to the data frame.

$$
\text { P_data=len }(X)-\operatorname{split2.}
$$

\section{RESULTS AND DISCUSSION}

We store the predictions made by the algorithm in the column. According on these signals we calculated the returns at the beginning of the day with the return at the opening.

Table 3. Sample Data Prediction result signal

\begin{tabular}{ll}
\hline Date & Signal \\
\hline $2019-02-17$ & 1 \\
$2019-02-18$ & 1 \\
$2019-02-19$ & 1 \\
$2019-02-20$ & 1 \\
$2019-02-21$ & 1 \\
$2019-02-22$ & 1 \\
$2019-02-23$ & 1 \\
\hline
\end{tabular}


Vol. 1, No. 1, March 2019

p-ISSN: 2656-5935 http://journal-isi.org/index.php/isi e-ISSN: 2656-4882

\begin{tabular}{ll}
\hline $2019-02-24$ & 1 \\
$2019-02-25$ & 1 \\
$2019-02-26$ & 1 \\
$2019-02-27$ & 1 \\
$2019-02-28$ & 1 \\
$2019-03-01$ & 1 \\
\hline
\end{tabular}

Finally, we calculated cumulative market returns \& cumulative strategy returns stored all results $\mathrm{n}$ df. After that, we look for the results of the sharpe ratio to make sure and pull out the performance.

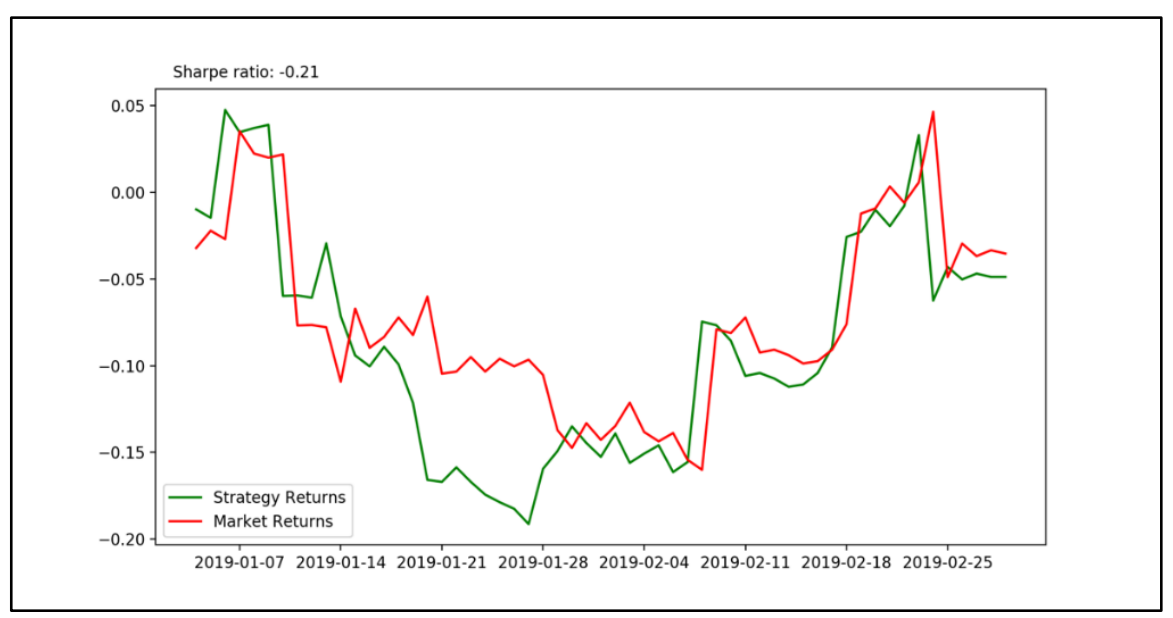

Figure 3. Strategy Return and Market Return

Based on Fig. 3 , we look and the result based on Strategy Return is $-0,05$ and market return is in $-0,03$, and prediction for $01-03-2019$ is still minus $-0,04$ so is not for investment on bitcoin for this day because the value is fall from 24-022019 it means negative on stock market. [10]

\section{CONCLUSION}

SVM and regime prediction can be use to predict current day's trend of Bitcoin on the market, but we need more knowledge to read the data, by expert on reader signal market and strategy return on the trading market. Future research we suggest to use deep learning such as ANN and other technical analytic ex. Market Technical Analysis that we mention on introduction to improve and provide the best results.

\section{REFERENCES}


[1] B. B. Worldwide, "The Bitcoin Volatility Index," 2018. [Online]. Available: https://www.buybitcoinworldwide.com/volatility-index/. [Accessed: 04Dec-2018].

[2] J. J. Murphy, "Technical Analysis Of The Financial Markets," Pennsylvania Dental Journal. 1999.

[3] A. Radityo, Q. Munajat, and I. Budi, "Prediction of Bitcoin exchange rate to American dollar using artificial neural network methods," in Advanced Computer Science and Information Systems (ICACSIS), 2017 International Conference on, 2017, pp. 433-438.

[4] B. J. de Almeida, R. F. Neves, and N. Horta, "Combining Support Vector Machine with Genetic Algorithms to optimize investments in Forex markets with high leverage," Appl. Soft Comput., vol. 64, pp. 596-613, 2018.

[5] L. Kašćelan, V. Kašćelan, and M. Jovanović, "Hybrid support vector machine rule extraction method for discovering the preferences of stock market investors: Evidence from Montenegro," Intell. Autom. Eamp; Soft Comput., vol. 21, no. 4, pp. 503-522, 2015.

[6] E. Su, "Stock index hedging using a trend and volatility regime-switching model involving hedging cost," Int. Rev. Econ. Financ., vol. 47, pp. 233-254, 2017.

[7] E. Panopoulou and T. Pantelidis, "Regime-switching models for exchange rates," Eur. J. Financ., vol. 21, no. 12, pp. 1023-1069, 2015.

[8] Varun Divakar, "Trading Using Machine Learning In Python - SVM (Support Vector Machine)," 2017. [Online]. Available: Trading Using Machine Learning In Python - SVM (Support Vector Machine). [Accessed: 10-Feb-2019].

[9] A. Greaves and B. Au, "Using the bitcoin transaction graph to predict the price of bitcoin," No Data, 2015.

[10] G. Saras, "Sekilas Tentang CAPM dan Cara Perhitungannya," 2017. [Online]. Available: https://rumahsaraswati.co/capm-dan-cara-perhitungannya/. [Accessed: 01-Mar-2019]. 